\title{
Impact of Displaced Cultural Traditions and Social Integration on Health-Related Behaviour among Migrant Women Living in Slovenia
}

\author{
MIRKO PROSEN, URŠKA BOGATAJ, IGOR KARNJUŠ, DOROTEJA REBEC, \\ SABINA LIČEN \\ Department of Nursing, Faculty of Health Sciences, University of Primorska, Polje 42, 6310 Izola, Slovenia \\ Email: mirko.prosen@fvz.upr.si
}

\begin{abstract}
Today's male dominance means migrant women are often overlooked in studies on migration. Cultural influences, socio-economic status and gender inequalities are strong predictors of health and health-related behaviour among migrant women; however, the existing models of women's health and care often overlook these predictors. The purpose of this study was to explore migrant women's experiences and perceptions about the impact of culture and social integration on their health and health-related behaviour in the host country. A descriptive qualitative study was conducted among ten hospital-admitted migrant women in Slovenia. The data were collected using semi-structured, one-to-one interviews. Two themes emerged from the analysis: (1) cultural values, beliefs and practices; and (2) social integration. For the majority of women in the study, migration has had a positive effect on their perceived physical and mental health. Some women have clearly become more empowered, moving them away from traditional norms and roles defined by patriarchy. Language barriers and social isolation increase the likelihood of health disparities, requiring these issues to be addressed in the future.
\end{abstract}

Keywords: culture, gender roles, language barriers, health care, health disparities

\section{INTRODUCTION}

In 2015, there were the estimated 244 million international migrants globally $(3.3 \%$ of the world's population), a rise from the estimated 155 million people in 2000 (2.8\% of the world's population). Europe and Asia each hosted around 75 million migrants in 2015 (62\% of all global international migrants). Most international migrants in 2015 were aged 20-64 years, with 52\% of all migrants being male and $48 \%$ female (International Organization for Migration 2017). However, in Slovenia female migrants who are either undocumented migrants or international protection-seekers and persons granted the international protection status represent a minority compared to their male counterparts (Ministry of Interior 2018), 
indicating a different migration flow. Namely, in Slovenia immigration from the states of former Yugoslavia prevails, having mostly started for economic reasons back in the 1960s and 1970s. Slovenia faced a bigger immigration wave, especially from the territory of Bosnia and Herzegovina, in the 1990s due to the war in the Balkans when over 70,000 refugees came, with some settling permanently, including from Kosovo. Like other EU member states in the last five-year period, Slovenia has been challenged by drastic migrations due to the conflicts in the Middle East and Africa. Yet, for most of these migrants, Slovenia remains principally a transition country. Between 2011 and 2018, the percentage of foreigners in the overall Slovenian population grew by $1.8 \%$ (from 4.1 to $5.9 \%$ ); in absolute terms, from 84,854 to 121,875 . In the same period, the number of foreign women rose considerably from 25,728 to 43,019 . As a share of the female population, it increased from $2.4 \%$ in 2011 to $4.1 \%$ in 2018 (Lenarčič, Sedmak 2019).

It is hence obvious that the proportion of migrant women is climbing and that, from a global perspective, women are slowly accounting for the majority of migrants in the world and have a set of specific push-and-pull factors which influence their decision to migrate. Building on the assumed dominance of males in migration patterns, women as migrants are often overlooked even though they represent, besides unaccompanied children, one of the most vulnerable migration groups (Adanu, Johnson 2009; de Leon Siantz 2013, Prosen et al. 2019). De Leon Siantz (2013) especially points out that the traditional status of migrant women has been often linked with their role and status within the family as children and is defined in relationship to their male partners as adults in many home countries. For this reason migration places women in an unknown situation where they experience stress, frustration and anxiety due to loss and separation from their established home, social and cultural settings. Their social integration, as de Leon Siantz further elaborates, in the host country may be equally limited to their initial lack of education, occupational and social experiences. In addition, migrants have to confront a new cultural context, and discover and understand the way the hosting society works, e.g. social norms, institutions, healthcare system, etc. The understanding of this situation should generate an adaptive response on the part of healthcare professionals who encounter migrants in the health system as well as the health system itself, given the intrinsic multicultural nature of migration (Perez Ramirez et al. 2013).

From the perspective of health, migration affects women's health by either worsening or improving their health, depending on the conditions in which the migration occurred, the extent of their integration, the social status of women in the host country, and the host-country living conditions (Adanu, Johnson 2009). Jayaweera (2018) esthablished that there is an abundance of evidence that women experience migration differently than men. Language barriers, the loss of social support mechanisms, longer family separation, sexual abuse and traumatic experience present only a handfull of risk factors, which affect already frail health status of migrant women. Furthermore, social isolation, discrimination and the burden of social and economic problems only make marginalisation worse (Ruppenthal et al. 2005; The Lancet Public Health 2018). In this context the ability of the health system to respond to the specific needs of migrant women rests on its ability to identify and prioritize those needs and associated risks. The increasing diversity of populations in Europe is therefore creating new challenges for health systems that then need to be adapted to remain responsive (Ruppenthal et al. 2005; Bogataj et al. 2019). All human beings have a right to the equal and 
prejudice free healthcare. Exclusion in any way from the health system for migrant women means in practice a delayed access to screening, treatment and care as well as a limited access to birth control and pregnancy termination, and heightened levels of discrimination and gender-based violence (Smith et al. 2016).

When seeking access to the health system, especially newly arrived migrants face barriers imposed by personal factors like age, gender, socio-economic status, ethnicity, language ability, proximity to healthcare services, social exclusion, health-seeking behaviour and health related beliefs. Along with barriers at the health system level like public health policy and the legal status of migrants within the host country's health system, specifics of the individual health system also have an impact (Hargreaves, Friedland 2013). By recognizing and overcoming at least some of these barriers, healthcare professionals strive to ensure a culturally sensitive care for migrant women (Prosen et al. 2019). Although the majority of healthcare professionals strive to deliver equal quality care to all of the patients, it needs to be emphasised that the appropriate and equal care means to assess patients' needs and address those needs (Dreachslin et al. 2012). The latter also includes addressing patients' cultural and social needs since it is a legal and moral obligation for healthcare professionals to be culturally competent in order to provide a culturally sensitive care (Repo et al. 2017). Studies have shown that healthcare professionals' experience of caring for cultural diverse patients is challenging and frustrating. In this aspect cultural knowledge and understanding of healthcare professionals about patients' culture is a crucial factor in providing a culturally sensitive care (Amiri et al. 2016). To serve the unique and diverse needs of patients it is imperative that nurses, midwives, medical doctors and other healthcare professionals understand the importance of cultural differences by valuing, incorporating and examining their own health-related values and beliefs and those of their health care organizations, for only then can they support the principle of respect for persons and the ideal of transcultural care (Bjarnason et al. 2009).

Yet, despite this, in their very simplicity the existing models of women's health and care fail to consider the cultural values, beliefs, norms, structural facilitators and constraints (de Leon Siantz 2013), that underpin the health and health-related behaviour of migrant women. A more integral view is needed to help health care professionals and researchers understand the multidimensional experiences, challenges and contexts that impact migrant women's health (de Leon Siantz 2013) if the culturally appropriate healthcare is to be provided. Therefore, the purpose of this study was to explore migrant women's experiences and perceptions concerning the impact of culture and social integration on their health and health-related behaviour in the host country.

\section{METHODS}

A descriptive qualitative study was conducted among hospital-admitted migrant women in Slovenia. The qualitative study formed part of the large-scale European Union regionally funded project Interreg V-A Italy-Slovenia 2014-2020 'Cross Boarder Network for Migrant Women: Social Integration, Sexual and Reproductive Health - INTEGRA' and focused on various aspects of migrant women's lives. The funding source had no role in the study design; the collection, analysis and interpretation of data; the writing of the manuscript; and in the decision to submit the manuscript for publication. The study was approved by the National Medical Ethics Committee (26.10.2017; No. 0120-544/2017/7). 


\section{Sampling and Recruitment}

The participants comprised a purposive sample after meeting the inclusion criteria of being a migrant woman in Slovenia and aged 18 years or older, able to overcome the language barrier (speaking English or any other Slavic language group) and willing to participate. It was also decided that the sample size would be monitored and determined by the saturation of data. The latter involves sampling until no new data are obtained and redundancy is reached (Polit, Beck Tatano 2018). We recruited participants from a maternity hospital located in the southwestern part of Slovenia from the end of January until the end of April 2018. The final sample included 10 migrant women.

\section{Data Collection}

The data were collected using semi-structured, one-to-one interviews. The interview guide was based on questions raised in the questionnaire (AIDOS et al. 2009) that was adapted for the quantitative research in the project INTEGRA. The questionnaire's basic form was in the Italian language. The questionnaire was translated from Italian to Slovenian. A group of three experts evaluated the translation over two rounds so that questions were later modified to fit the form of interview questions as well as to fit the Slovenian cultural context for certain questions on social integration. The interview guide was exhaustive in questions and aimed, for the purposes of this part of the study, at understanding the influence of cultural background (traditions, family and society), migration process and social integration on perceived and experienced health and health-related behaviour. Questions and sub-questions were retrospective and prospective in nature and moved from the general to the specific ones. Some sample questions are 'Tell me about traditions and cultural habits in your culture'; 'Tell me about the preservation of your traditions and cultural habits in Slovenia'; 'Tell me about your role as a woman in your home country and your role now'; 'Tell me about the influence of religion in your everyday life'; 'Tell me about your living conditions before and now'; 'Tell me about any changes in your health (or the health of your family) that occurred after your arrival'; 'Tell me about your ties with the local community or your cultural group'; 'Tell me about your contact with health care providers in your local community after your arrival', etc.

Potential participants, those who spoke the English language or a language the interviewer understood (Slavic group languages), were approached by midwives in the maternity hospital. The participants were advised the purpose of the study and the methods used, including that the interview would be audio-recorded. They were all assured anonymity, confidentiality and that they could withdraw from the study at any time without any consequences for them here. Two women (Kosovo) felt they needed to ask their husbands for approval but were denied from doing so. The interviews took place in a hospital room. The most suitable time was agreed with the participants prior to the interview, noting that some women had been admitted to the ward following childbirth and that confidentiality and wellbeing also had to be considered during the interview. Before the interviews started, the women gave their written consent. For three women, their spoken language was Slovenian, for three it was English, for another three Slovenian and partly Serbian, and for another Slovenian and partly English. A combination of two languages was used to explain things not understood well. No interpreter was present in any interview, nor was any other person (e.g. a husband), neither was such a wish expressed. On average, the interviews lasted $39 \mathrm{~min}$, the shortest being 18 min and the longest $71 \mathrm{~min}$. After each interview, the recording was given a unique code and 
that was later used to refer to that interview. In addition, after each interview the interviewer (all were female) prepared a reflection report on the interview, observations and impressions.

\section{Data Analysis}

All interviews were digitally audio-recorded and transcribed verbatim. During the transcription process, the names of persons, specific places or institutions were anonymized. Before inputting the transcripts into the computer software program NVivo 10 (QRS International, Victoria, Australia), they were once again compared with the audio-recording. The transcribed data were analysed using a thematic analysis, which relates to the process of analysing data in relation to communalities, differences and relationships (Gibson, Brown 2009; Polit, Beck Tatano 2018). The smaller units of data were coded for descriptive labels and then grouped based on a shared concept, e.g. meaning units (Polit, Beck Tatano 2018), building on themes and subthemes. Due to the abundance of data not focused on the research question, a data reduction was undertaken to sharpen, sort, focus, discard and organize the data (Miles, Huberman 1994). The transcripts were analysed by the first author and verified by the last author.

\section{RESULTS}

\section{Participants}

The ten women aged 22-37 years (mean age 30.5 years) who participated in the study had migrated from Bosnia and Herzegovina (3), Russia (2) and Serbia (2), Ukraine (1), Kosovo (1) and Iran (1). The reason for migration for six of them was to re-join a family member (in the majority of cases their husband) and for one it was to be married. Three women migrated for job opportunities and education. Six women had finished the upper secondary education, one the high school and three had the university level. Regarding living conditions, more than half $(n=6)$ of them lived in a rented apartment in an urban area. At the time of the study, the average household included 3.2 members. All women, with the exception of one, held valid health insurance provided by the Republic of Slovenia. Regarding obstetrics anamnesis, eight women were primipara and two were multipara. Nine of them gave birth in Slovenia in 2018. The average age of the first-time mothers was 28.80 years. The youngest gave birth in their 20 s and the oldest was aged 37.

\section{Thematic Analysis}

Two themes emerged from the analysis: (1) cultural values, beliefs and practices; and (2) social integration.

\section{Cultural Values, Beliefs and Practices}

This theme comprehensively describes culture and traditions that directly and indirectly influence health and health-related behaviour in the host country. Family life for the majority of women, after they migrated, retained the traditional form, although for most of them their migration brought a more liberal role. However, life-time events such as marriage, family gatherings, religious or national holidays remain very important events for cultural identity. Some of these celebrations relate to eating habits that cannot be characterized as healthy (e.g. high-fat food and sugar use, alcohol intake) and are mainly described by women from the Balkan region. 
'You know... The more holidays there are the better. There is a need for celebration, to eat as much as possible, to drink, to visit relatives and so on.' (INTE_22_1_SRB)

Along with the preserved traditions, it is clear that religion still plays a pivotal role in the life of most participants. It influences their life throughout their life span; yet, in some cases migration meant that religion had become less influential in some aspects of women's lives. This was noticeable when a woman had over a longer time become less involved in religious life in the host country, whereas among newly arrived migrants this was not the case. Religion's influence on health was perceived directly as positive and no participant discussed the negative effects. A Muslim woman from Kosovo perceived the influence of religion as positive:

'Religion helps me stay grounded...Unfortunately, you see many young people abusing alcohol here in Slovenia...' (INTE_23_1_KOS)

Even though the women were reluctant to speak about religion and its broader effects on their health and health-related behaviour, it was indirectly noticeable that it affects their family roles, social position and their autonomy. The use of contraception, for example, was often pointed out as a choice that is not solely up to the woman, but also with the agreement of the husband and, in one specific case, where only the husband decides.

'The use of any kind of contraception is a decision that must be made by the husband.' (INTE_35_3_BIH)

The discussion on contraception also revealed another issue hazardous to migrant women's health. One woman described the use of oral contraception of questionable efficacy:

'I use homeopathic medicines and other herbs. In Slovenia, they are hard to get. It is easier in Ukraine, although they were some time ago forbidden for use.' (INTE_32_1_UKR)

The intensity of gender-defined roles seems to be a strong predictor of migrant women's health and health-related behaviour. The patriarchal model is still embedded in the family structures of the majority of the interviewed migrant women, even though they were reluctant to admit it. Its existence defines a woman's socio-economic status, which then affects her health and can be the cause of health disparities in the host country. Most women confessed that gender roles still dictate that the 'woman is responsible for taking care of the household' and is (and remains) the principal carer with respect to the children or any other family member.

'In Russia, the man is the boss of the family and the woman takes care of the household. In Slovenia this is not the case. A woman takes care of the whole family and, on top of that, even of the man (laughs), in my way of thinking, this is not normal...' (INTE_37_1_RU)

'Some families have a lot of stock and they have to take care of everything, they do not stop from dawn till evening. It's easier for men since they come home from work and everything is waiting ready for them.' (INTE_22_1_SRB)

'I stay at home. I think I have to learn the language... I would like to go to school. Now I have a newborn...this is a problem...we will see.' (INTE_23_1_KOS)

Another issue touching on culture and male dominance the women highlighted is the existence of family violence, which deeply impacts physical and mental health. Although the migrant women emphasized several times that violence never occurred in their family, family violence seems common and the feeling arises that this is not something that was left behind in the home country.

'A woman gets slapped quite frequently...' (INTE_22_1_SRB)

'There is a lot of family violence. I didn't have to face this; although there are many men who are violent to their wives.' (INTE_35_3_BIH) 
'Family violence is very much part of our culture. Within the family, women tolerate this...' (INTE_37_1_RU)

'Family violence is present in certain families; but this was not the case in my family. I always saw a role model in my father.' (INTE_23_1_KOS)

\section{Social Integration}

All of the interviewed women are trying to retain their cultural identity in the host country, except for one who claimed that:

'all migrants should put aside their culture when settling in another country'. (INTE_32_1_BIH)

This also entails retaining one's cultural beliefs and attitudes to health; however, among those migrant women who have been living in Slovenia for a year or longer there are signs that they are trying to integrate the host country's cultural traditions into their life. The previously mentioned eating habits are an example of such a change.

'My shopping habits have changed. The prices are higher, but the quality of food is much higher. Here I even don't have to check the expiry date because I'm sure it is OK... My husband and I are still trying to keep our Ukrainian culinary habits, but we are introducing Slovenian cuisine.' (INTE_32_1_UKR)

From the perspective of health-related behaviour, social support seems to be problematic for certain groups of women. Social support is the key to changing and influencing women in the area of health promotion, although women from Kosovo, for example, remain socially isolated, mostly due to the cultural and language barriers.

'I have no friends. I have had to do everything by myself. I haven't met any Muslims here... I knew a few people from Kosovo who lived here, but they do not any more... My husband has an aunt in Slovenia, but she lives too far away. My husband is my support.' (INTE_23_1_KOS)

The already mentioned language barriers pose a great obstacle not only in the efforts to integrate into society but also in accessing health care services. Among all interviewed women, the women who speak Albanian had the most problems communicating with health care professionals.

'I understand that Albanian is harder to understand than other languages in the Balkan area and also that is hard to get someone who would understand and translate... I try to speak English, but some nurses looked at me as if they were angry they had to speak English. I do not know why... Perhaps because I'm a foreigner.' (INTE_23_1_KOS)

The women's quality of life has changed after their migration, although not all dimensions of quality of life have been equally affected. Social and living conditions, health status and wellbeing have improved significantly, while other social aspects like low social support and security, economic dependence and the existence of prejudice are factors that in many of the women's eyes inhibit quality of life. They are hence also the factors that create health disparities.

\section{DISCUSSION}

Health beliefs are formed and health practices are enacted within the context of everyday life, e.g. within their cultural and social worlds. Health by itself is often defined by people from various cultural surroundings as the absence of illness and is based on personal perceptions of wellbeing and personal health; family and cultural health beliefs and practices; sociocultural 
systems of beliefs and practices in a dynamic interaction within the context of the environment where they live; and the beliefs about their structure and functions of the body as well as body boundaries (Anderson et al. 2010). The migration process itself influences cultural changes by moving existing cultural boundaries and aligning them with the culture of the host country. In some cases, these changes can be considerable and in others not, depending on the ethnic group and the host country. When discussing culturally-based beliefs about health and health-related behaviour, these changes can bring both positive and negative effects for one's health status. For the majority of women in the study, their migration had a positive impact on their perceived physical and mental health. Some women had clearly become more empowered, moving them away from traditional norms, the patriarchal model and gender defined roles. This was especially true for women who had migrated in search of economic improvement or education. On the other hand, this process seems to be very slow for the interviewed women whose life remains very much defined by the patriarchy and whose reason to migrate was to re-join a family member (husband). However, some emancipatory patterns were already noticeable among those living in Slovenia for a year or longer.

Social isolation is another problem encountered by migrant women since it relates directly with health, access to health care services and overall quality of life. Exclusion in any way from health care means that migrant women face a delayed access to screening, treatment and care, a limited access to contraception and pregnancy termination, and greater levels of discrimination and violence, all of which affect women's health and contribute to the development of health disparities (Smith et al. 2016). Among other factors like lack of education, occupational and social experiences (de Leon Siantz 2013), the language barrier only exacerbates this exclusion from health care services and public life and increases woman's dependence on her husband.

It is crucial to understand the social factor underpinning migrant women's life in the host country if the culturally appropriate health care is to be provided. Health care services must therefore be adapted to migrant women's expectations of support and cultural differences. Although the majority of women in the study reported better wellbeing after arriving in the host country, some issues need to be further addressed in efforts to improve migrant women's health. Many of these issues directly relate to the social determinants of health and public policies that affect migrant women's lives and legal status. The implications of these findings suggest that health care institutions should more carefully address the language barrier issue by re-examining their current practices, providing translations of health promotion/health education material, using pictograms and introducing social/cultural anamnesis as part of patients' medical history, introduce cultural-mediator services whenever possible, etc. Health care institutions should work closely with community nurses and social care workers in assisting migrant women to settle into the community. The role of the community nurse should be attributed with greater importance by including migrant women in community-based health programs and national screening schemes and raise awareness not only about health issues and how to access the health care system, but also about family violence and possible solutions. Educational institutions training future health care professionals should include cultural content in the formal curriculum as well as introduce a life-long learning module for health care professionals and support staff working in health institutions (Prosen et al. 2018; Prosen et al. 2019).

The socio-cultural environment and its impact on migrant women's health needs after they migrate are poorly understood. This study adds to understanding of how migrant women's culture in the context of patriarchy altered gender roles and a new cultural environment 
influences and acts with respect to the health status and health-related behaviour. Based on the findings, some solutions are offered that may help in delivering culturally sensitive care, improving migrant women's health, and combatting health disparities. Nevertheless, our study has some limitations that are common to all qualitative studies. The study used a purposive sample which might reflect selection bias, although the migrant women were chosen, besides their willingness to participate, solely on the basis of their communication skills and spoken language. Since the interviews were conducted in a hospital environment, this may have influenced the women's opinion on certain matters, yet this decision was made because it would be difficult to ensure truthful answers if the interviews were conducted at home due to the presence of the husband.

More research is needed to explore individual social determinants of migrant women's health and the health of their family members, gender-based barriers to accessing health care, including health care professionals' beliefs and attitudes regarding migrants. The health literacy of migrant women also deserves further examination in the future.

Received 11 January 2019 Accepted 6 June 2019

\section{References}

1. Adanu, R. M.; Johnson, T. R. 2009. 'Migration and Women's Health', International Journal of Gynaecology and Obstetrics 106(2): 179-181.

2. AIDOS; ADUSU; Culture aperte. 2009. Mutilazioni dei genitali femminili e diritti umani nelle communita migranti: Rapporto di ricerca nelle regioni Veneto e Friuli Venezia Giulia. Available at: https://www.aidos.it/wp-content/uploads/2009/01/MGF-rapporto-ricercacomunit\%C3\%A0-migranti-_ok-1.pdf (cited 24.07.2018).

3. Amiri, R.; Heydari, A.; Dehghan-Nayeri, N.; Vedadhir, A. A.; Kareshki, H. 2016. 'Challenges of Transcultural Caring Among Health Workers in Mashhad-Iran: A Qualitative Study', Global Journal of Health Science 8(7): 203-211.

4. Anderson, N. L. R.; Andrews, M.; Bent, K. N.; Douglas, M. K.; Elhammoumi, C. V.; Keenan, C.; Kemppainen, J. K.; Lipson, J. G.; Thompson Martin, C.; Mattson, S. 2010. 'Chapter 5: Culturally Based Health and Illness Beliefs and Practices Across the Life Span', Journal of Transcultural Nursing 21(4 Suppl.): 152S-235S.

5. Bjarnason, D.; Mick, J.; Thompson, J. A.; Cloyd, E. 2009. 'Perspectives on Transcultural Care', Nursing Clinics of North America 44(4): 495-503.

6. Bogataj, U.; Prosen, M.; Karnjuš, I.; Rebec, D.; Ličen, S. 2019. 'Current Issues and Future Possibilities for Improving Healthcare for Migrant Women in Slovenia', in Women, Migrations and Health: Ensuring Transcultural Healthcare, eds. S. Ličen, I. Karnjuš, M. Prosen. Koper: University of Primorska Press, 107-116.

7. De Leon Siantz, M. L. 2013. 'Feminization of Migration: A Global Health Challenge', Global Advances in Health and Medicine 2(5): 12-14.

8. Dreachslin, J. L.; Gilbert, M. J.; Malone, B. 2012. Diversity and Cultural Competence in Health Care: A Systems Approach. Somerset: John Wiley \& Sons Incorporated.

9. Gibson, W. J.; Brown, A. 2009. Working with Qualitative Data. London: Sage.

10. Hargreaves, S.; Friedland, J. S. 2013. 'Impact on and Use of Health Services by New Migrants in Europe', in Migration, Health and Inequality, eds. F. Thomas, J. Gideon. London, New York: Zed Books, $27-43$.

11. International Organization for Migration. 2017. World Migration Report 2018. Geneva: International Organization for Migration.

12. Jayaweera, H. 2018. 'Access to Healthcare for Vulnerable Migrant Women in England: A Human Security Approach', Current Sociology 66(2): 273-285.

13. Lenarčič, B.; Sedmak, M. 2019. 'Reproductive Health of Migrant Women in Slovenia: State of the Art', in Women, Migrations and Health: Ensuring Transcultural Healthcare, eds. S. Ličen, I. Karnjuš, M. Prosen. Koper: University of Primorska Press, 35-58.

14. Miles, M. B.; Huberman, M. A. 1994. Qualitative Data Analysis: An Expanded Sourcebook. Thousand Oaks: Sage. 
15. Ministry of Interior. 2018. Police Activities in Connection with Current Migration Flows - Available Information. Available at:https://www.policija.si/eng/index.php/component/content/article/13-news/1729-a-new-webpage-on-police-activities-re-current-migration-flows-set-up-available-informations (cited 27.12.2018).

16. Perez Ramirez, F.; Garcia-Garcia, I.; Peralta-Ramirez, M. I. 2013. 'The Migration Process as a Stress Factor in Pregnant Immigrant Women in Spain', Journal of Transcultural Nursing 24(4): 348-354.

17. Polit, D. F.; Beck Tatano, C. 2018. Essentials of Nursing Research: Appraising Evidence for Nursing Practice. 9th edn. Philadelphia: Wolters Kluwer Health.

18. Prosen, M.; Ličen, S.; Bogataj, U.; Rebec, D.; Karnjuš, I. 2019. 'Migrant Women's Perspective on Reproductive Health Issues and Their Healthcare Encounters' in Women, Migrations and Health: Ensuring Transcultural Healthcare, eds. S. Ličen, I. Karnjuš, M. Prosen. Koper: University of Primorska Press, 117-138. 19. Prosen, M.; Ličen, S.; Rebec, D.; Bogataj, U.; Medica, K.; Čelhar, J.; Prosen, J.; Podobnik, M.; Mugoša, M.; Stegel Bizjak, M.; Karnjuš, I. 2018. Report About the Migrant Women's Population Characteristics, Their Sexual and Reproductive Health and Social Integration: The Case of Slovenia. Izola: Faculty of Health Sciences, University of Primorska.

20. Repo, H.; Vahlberg, T.; Salminen, L.; Papadopoulos, I.; Leino-Kilpi, H. 2017. 'The Cultural Competence of Graduating Nursing Students', Journal of Transcultural Nursing 28(1): 98-107.

21. Ruppenthal, L.; Tuck, J.; Gagnon, A. J. 2005. 'Enhancing Research with Migrant Women through Focus Groups', Western Journal of Nursing Research 27(6): 735-754.

22. Smith, A. C.; LeVoy, M.; Mahmood, T.; Mercer, C. 2016. Migrant Women's Health Issues: Addressing Barriers to Access to Health Care for Migrant Women with Irregular Status. Available at: https://www.euro.who. int/__data/assets/pdf_file/0017/330092/6-Migrant-womens-health-issues-irregular-status.pdf?ua=1 (cited 14.07.2018).

23. The Lancet Public Health. 2018 'Protecting Migrant Women', The Lancet Public Health 3(1): e1.

MIRKO PROSEN, URŠKA BOGATAJ, IGOR KARNJUŠ, DOROTEJA REBEC, SABINA LIČEN

\section{Kultūrinių tradicijų ir socialinès integracijos poveikis Slovẻnijoje gyvenančių moterų imigrančių su sveikata susijusiam elgesiui}

